\title{
Hypertension in Black Africans with Autosomal Polycystic Kidney Disease
}

Sidy Mohamed Seck ${ }^{1 *}$, Mouhamadou Moustapha Cisse ${ }^{2}$, Elhadj Fary $\mathrm{Ka}^{2}$, Ibrahima Diallo ${ }^{1}$, Serigne Gueye ${ }^{2}$ Abdou Niang $^{2}$ and Boucar Diouf $^{2}$

${ }^{1}$ Internal Medicine and Nephrology, University Gaston Berger Saint-Louis, Senegal

${ }^{2}$ Nephrology Department, University Hospital Aristide Le Dantec Dakar, Senega

\begin{abstract}
Introduction:High blood pressure (HBP) that is a leading cause of end-sage renal disease (ESRD) in black African populations and is frequently associated to autosomal polycystic kidney disease (ADPKD). This study aimed to describe prevalence and severity of HBP in black Africans with ADPKD and to identify associated risk factors.

Patients and methods: We performed a retrospective study of 65 ADPKD patients regularly followed in outpatient nephrology clinic between 1995 and 2009. ADPKD was diagnosed according to recent unified criteria (2009). Statistical analyses were done with SPSS 16.0.

Results: We included 65 patients (36 males and 29 females) with a mean age of $47 \pm 5$ years. Hypertension was found in $73.8 \%$ of patients and it preceded diagnosis of ADPKD in 23 patients (median delay of 28 months). Mean systolic/diastolic blood pressure was $168 \pm 30 / 96 \pm 16 \mathrm{~mm} \mathrm{Hg}$ respectively. All hypertensive patients presented retinopathy and left ventricular hypertrophy. Two patients presented stroke. Fifty one percent of patients were treated with angiotensin converting enzyme inhibitors alone and $29 \%$ received combinations of anti-hypertensive drugs. One third of them had their blood pressure normalized. Patients with HBP at diagnosis showed a similar proportion of ESRD in comparison with normotensive patients $(p=0.12)$. At univariate analysis, HBP was correlated with age, gender, BMI, GFR and proteinuria. Multiple regression analysis identified age $(O R=1.95, p=0.05)$ and glomerular filtration rate $(O R=2.33, p=0.001)$ as independently associated to HBP.
\end{abstract}

Conclusion: Hypertension with organ damage is frequent in Senegalese patients with ADPKD. Age and glomerular filtration rate at diagnosis were the main risk factors of HBP identified in our patients.

Keywords: Hypertension; Polycystic kidney disease; Black Africans

\section{Introduction}

Autosomal polycystic kidney disease (ADPKD) is the most common hereditary renal disease but it is rarely described in black African populations [1,2]. High blood pressure (HBP) is a leading cause of end-sage renal disease (ESRD) in this population and is frequently associated to ADPKD [3,4]. Patients with ADPKD usually develop HBP prior to impairment of glomerular filtration rate (GFR) $[5,6]$ and its complex pathogenesis involves cyst growth, renal volume and many other hemodynamic and neuro-endocrine factors [4,7]. Moreover, once present, HBP can worsen the cardiovascular and renal prognosis [8].

This study aimed to describe prevalence and severity of HBP in black Africans with ADPKD and to identify associated risk factors.

\section{Patients and Method}

We performed a retrospective and descriptive study of 65 ADPKD patients regularly followed-up in outpatient nephrology clinic between 1995 and 2009. Socio-demographic, clinical and paraclinical data were collected from medical records that included first outpatient visit (or admission) and routine visits. Patients were followed-up on a yearly basis, or more frequently if required. All diagnosis of ADPKD were reviewed according to ADPKD unified criteria [9]. HBP was defined and stratified according to seventh Join National Committee report [10]. Patients with incomplete records and those who did not met ADPKD criteria were not included. Statistical descriptive and correlation analyses were done with SPSS11.0.

\section{Results}

We included 65 patients ( 36 males and 29 females) with a mean age of $47 \pm 5$ years. Hypertension was found in $73.8 \%$ of patients and it preceded the diagnosis of ADPKD in $28.8 \%$ of them (median delay of 28 months between HBP and ADPKD diagnosis). Levels of blood pressure in our patients are presented in Figure 1. Mean serum creatinine and

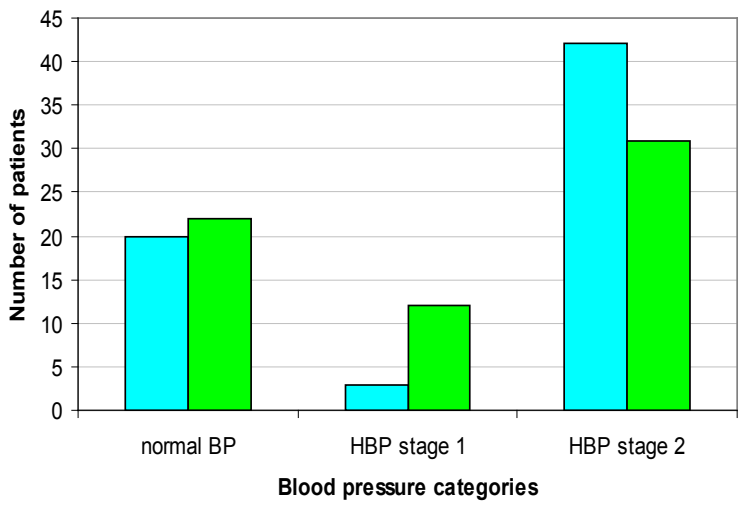

$\square$ Systolic blood pressure $\quad \square$ Diastolic blood pressure

Figure 1: Blood pressure categories in our patients.

*Corresponding author: Sidy M Seck, Internal Medicine and Nephrology, University Gaston Berger 234 Route de Ngallèle, Saint-Louis, Senegal, Tel: 00221 775667901; Fax: 00221 339611884; E-mail: sidy-mohamed.seck@ugb.edu.sn

Received July 09, 2011; Accepted August 22, 2011; Published August 25, 2011

Citation: Seck SM, Cisse MM, Ka EF, Diallo I, Gueye S, et al. (2011) Hypertension in Black Africans with Autosomal Polycystic Kidney Disease. J Nephrol Therapeutic 1:102. doi:10.4172/2161-0959.1000102

Copyright: @ Seck SM, et al. This is an open-access article distributed under the terms of the Creative Commons Attribution License, which permits unrestricted use, distribution, and reproduction in any medium, provided the original author and source are credited. 
GFR were respectively $3.45 \pm 1.4 \mathrm{mg} / \mathrm{dl}$ and $45 \pm 13 \mathrm{ml} / \mathrm{min}$. Differences between hypertensive and normotensive patients in clinical, biological and ultrasound findings at diagnosis are presented in Table 1.

Proliferative retinopathy was present among all 35 hypertensive patients who underwent fundoscopic examination. Two patients presented cerebral ischemia secondary to HBP. At univariate analysis, age $(\mathrm{r}=1.45 ; \mathrm{p}=0,02)$, gender $(\mathrm{r}=0.98 ; \mathrm{p}=0,04)$, BMI $(\mathrm{r}=0.85 ; \mathrm{p}=0,02)$, GFR $(\mathrm{r}=2.56 ; \mathrm{p}=0,001)$ and proteinuria $(\mathrm{r}=1.86, \mathrm{p}=0,02)$ were significantly correlated to HBP. Multiple regression analysis identified age $(\mathrm{OR}=1.95, \mathrm{p}=0.05)$ and glomerular filtration rate $(\mathrm{GFR})(\mathrm{OR}=2.33$, $\mathrm{p}=0.001)$ as independently associated to hypertension.

Anti-hypertensive therapy for the majority of patients comprised ACE inhibitors alone or in combination with other drugs (Figure 2). However only $50 \%$ of them had their blood pressure in $<140 / 90 \mathrm{~mm}$ Hg. After a median follow-up of 96.8 months, incidence of ESRD was not different between hypertensive and normotensive patients (respectively $60 \%$ versus $50 \%, \mathrm{p}=0.12$ ). But mortality was higher in the hypertensive group ( 17 versus 5 cases, $\mathrm{p}=0.03$ ).

\section{Discussion}

ADPKD is probably an underestimated health issue in Senegalese population with an estimated hospital prevalence of $0.2 \%$ [2]. The high prevalence of hypertension in our patients was similarly found in previous studies where HBP concerned 50 to $75 \%$ of patients with ADPKD [3,4,6,11]. However, in Morocco where ADPKD represents $6.5 \%$ of dialysis patients, lower prevalence of HBP (11\%) was reported [12]. This variability between studies is probably due to differences in genotype and diagnosis delay. In fact, frequency of HBP was higher in our patients compared to other series [11] probably because of delayed diagnosis of ADPKD (more cyst volume and lower GFR) [13]

\begin{tabular}{|c|c|c|c|}
\hline Characteristics & $\begin{array}{l}\text { Hypertensives } \\
\mathrm{n}=48\end{array}$ & $\begin{array}{l}\text { Normotensives } \\
\mathrm{n}=17\end{array}$ & $\mathrm{P}$ \\
\hline Age (years) & $45 \pm 12$ & $50 \pm 14$ & 0.23 \\
\hline Sex-ratio (male/female) & 1.5 & 0.43 & 0.03 \\
\hline Body mass index $(\mathrm{kg} / \mathrm{m} 2)$ & 28 & 26 & 0.98 \\
\hline \multirow[t]{2}{*}{ Blood pressure } & $181 \pm 22$ & $130 \pm 5$ & 0.001 \\
\hline & $103 \pm 12$ & $75 \pm 5$ & 0.001 \\
\hline Glomerular filtration rate $(\mathrm{ml} / \mathrm{mn})^{*}$ & $34.3 \pm 16$ & $40.8 \pm 10$ & 0.10 \\
\hline Hemoglobin $(\mathrm{g} / \mathrm{dL})$ & 9.7 & 10.5 & 0.86 \\
\hline Proteinuria (g/day) & 1.05 & 0.95 & 0.76 \\
\hline Left ventricular hypertrophy & $100 \%$ & $60 \%$ & 0.04 \\
\hline Kidney size $(\mathrm{mm})^{\star *}$ & $153 \pm 25$ & $145 \pm 21$ & 0.61 \\
\hline
\end{tabular}

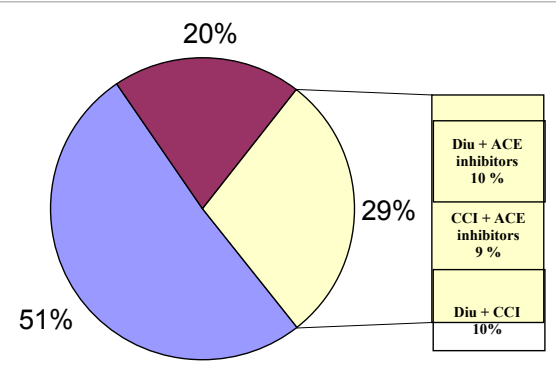

$\square$ ACE alone

$\square \mathrm{CCl}$ alone

口Combinations

ACE: angiotensin conversion enzyme inhibitors

CCl: calcium channel inhibitors

Diu= diuretics

Figure 2: Anti-hypertensive treatment in our patients. even though in $60 \%$ of patients increase of blood pressure precedes GFR decline years before [14]. Also, patients with PKD1 mutations or with an hypertensive ascendant are at higher risk to develop HBP and earlier in their life [4]. Occurrence of hypertension in ADPKD results from an interplay between many factors such as cyst growth and increase in renal vascular resistance and filtration fraction, activation of peripheral renin-angiotensin system, salt sensitivity, extracellular fluid overload, resetting of the pressure-natriuresis relationship [13]. An early decrease in renal blood flow is noticed in young ADPKD patients before development of HBP [15].

LVH was more frequent in hypertensives patients compared to normotensives. LVH may occur in ADPKD patients without HBP but HBP can also increase risk of $\mathrm{LVH}$ achieving $70 \%$ of ADPKD patients at ESRD [16]. However, the retrospective nature of our study could not help to distinguish whether LVH preceded or was secondary to HBP. Only $30 \%$ of our patients had their blood pressure in the normal ranges despite anti-hypertensive treatments. Poor blood pressure control increases the risk for $\mathrm{LVH}$, proteinuria, ESRD and cardiovascular morbi-mortality [4]. The superiority of an anti-hypertensive drug in ADPKD is not yet clearly established. Blockers of renin-angiotensin system can efficiently help controlling blood pressure in ADPKD patients, regression of LVH [13] and might also reduce cyst progression and GFR decline [17]. Due to this hypothetical benefit, ACE inhibitors were the most prescribed anti-hypertensive drugs in our patients.

Kidney size was not a predictor of HBP in our patients but ultrasonography is not a recommended method to assess kidney volume. Magnetic resonance imaging is the best technique but it was not available in this study. In fact, many studies have demonstrated a correlation between hypertension, left ventricular hypertrophy, cyst volume progression and deterioration of GFR [13]. Albuminuria and GFR might be markers of underlying vascular damages in ADPKD like in general population [18].

Early detection and treatment of hypertension in ADPKD is an important clinical issue because it can reduce cardiovascular complications which are the main causes of death in the post-dialysis era $[13,19]$.

\section{Conclusion}

Hypertension with organ damage is frequent in black African patients with ADPKD. In the majority of cases diagnosis is delayed with impaired renal function. Main risk factors are age, male sex and low GFR. Blood pressure control is poor but adherence to therapy can be a confounding factor in our patients with low economic level.

\section{References}

1. Torres VE, Harris PC, Pirson Y (2007) Autosomal dominant polycystic kidney disease. Lancet 369:1287-301.

2. Ka EF, Seck SM, Cisse MM, Niang A, Diouf B (2010) Patterns of polycystic kidney diseases in black Africans. Saudi J Kidney Dis Transpl 21:81-86.

3. Gabow PA, Chapman AB, Johnson AM, Tangel DJ, Duley IT (1990) Rena structure and hypertension in autosomal dominant polycystic kidney disease. Kidney Int 38:1177-1180.

4. Chapman AB, Stepniakowski K, Rahbari-Oskoui F 2010 Hypertension in Autosomal Dominant Polycystic Kidney Disease. Adv Chronic Kidney Dis 17:153-163.

5. Kelleher CL, McFann KK, Johnson AM, Schrier RW (2004) Characteristics of hypertension in young adults with autosomal dominant polycystic kidney disease compared with the general U.S. Population. Am J Hypertens 17:1029 1034. 
Citation: Seck SM, Cisse MM, Ka EF, Diallo I, Gueye S, et al. (2011) Hypertension in Black Africans with Autosomal Polycystic Kidney Disease. J Nephrol Therapeutic 1:102. doi:10.4172/2161-0959.1000102

6. De Almeida EA, Prata MM (2007) Hypertension in autosomal dominant polycystic kidney disease: observational study in 207 patients with a mean follow-up of 107 months. Rev Port Cardiol 26:1173-82.

7. Wang D, Strandgaard S (1997) The pathogenesis of hypertension in autosomal dominant polycystic kidney disease. J Hypertens 15:925-933.

8. Gabow PA, Johnson AM, Kaehny WD, Kimberling WJ, Lezotte DC, et al. (1992) Factors affecting the progression of renal disease in autosomal-dominant polycystic kidney disease. Kidney Int 41: 1311-1319.

9. Pei Y, Obaji J, Dupuis A, Paterson AD, Magistroni R, et al (2009) Unified criteria for ultrasonographic diagnosis of ADPKD. J Am Soc Nephrol 20: 205-12.

10. Chobanian AV, Bakris GL, Black HR, Cushman WC, Green LA, et al. (2003) Seventh report of the Joint National Committee on Prevention, Detection, Evaluation, and Treatment of High Blood Pressure. Hypertension 42:12061252.

11. Kazancioglu R, Ecder T, Altintepe L, Altiparmak MR, Tuglular S, et al. (2011) Demographic and clinical characteristics of patients with autosomal dominant polycystic kidney disease: a multicenter experience. Nephron Clin Pract 117: $270-275$

12. Bourquia A (2002) Autosomal dominant polycystic kidney disease (ADPKD) in Morocco. Multicenter study about 308 families. Nephrologie 23: 93-96.

13. Schrier RW (2009) Renal volume, renin-angiotensin-aldosterone system, hypertension, and left ventricular hypertrophy in patients with autosoma dominant polycystic kidney disease. J Am Soc Nephrol 20:1888-1893.

14. Ecder T, Schrier RW (2009) Cardiovascular abnormalities in autosomaldominant polycystic kidney disease. Nat Rev Nephrol 5: 221-228.

15. Torres VE, King BF, Chapman AB, Brummer ME, Bae KT, et al. (2007) Magnetic resonance measurements of renal blood flow and disease progression in autosomal dominant polycystic kidney disease. Clin J Am Soc Nephrol 2: 112 120

16. Bardaji A, Martinez-Vea A, Valero A, Gutierrez C, Garcia C, et al. (2001) Cardiac involvement in autosomal-dominant polycystic kidney disease: a hypertensive heart disease. Clin Nephrol 56: 211-120.

17. Chapman AB, Torres VE, Perrone RD, Steinman TI, Bae KT, et al. (2010) The HALT polycystic kidney disease trials: design and implementation. Clin J Am Soc Nephrol 5:102-109.

18. Chronic Kidney Disease Prognosis Consortium, Matsushita K, van der Velde M, Astor BC, Woodward M, et al. (2010) Association of estimated glomerular filtration rate and albuminuria with all-cause and cardiovascular mortality in general population cohorts: a collaborative meta-analysis. Lancet 375: 20732081.

19. Rahman E, Niaz FA, Al-Suwaida A, Nahrir S, Bashir M, et al. (2009) Analysis of causes of mortality in patients with autosomal dominant polycystic kidney disease: a single center study. Saudi J Kidney Dis Transpl 20: 806-210. 